\title{
Psychological Health Education Mode for University Students from the Perspective of New Media
}

\author{
Jiying Wang ${ }^{1 *}$ \\ 1 Jiangsu Open University, Nanjing, 210036, CHINA
}

Received 15 July 2017 • Revised 13 October 2017 • Accepted 12 November 2017

\begin{abstract}
With the continuous development of science and technology, new media such as the internet and smart phones has become part of people's life, and has gained a fast popularity, especially to university students. The emergence of new media will have direct and indirect influence on university students' psychological health and bring some unpredictable impact. Most of research focused partially on new media or psychological health education mode for university students, in order to undertake further research and improve related theory, based on the comprehensive research of literature review, this paper adopts spass2010 software's principal component analysis to deal with the data and analyze the received questionnaires, then it compares and discusses the positive and negative influence on psychological health education that has been brought with new media to university students. On the basis of full consideration of real situation, this paper provides some aspects that need to be improved on psychological health education mode for university students from the perspective of new media, such as the construction of comprehensive education system, enriching the education content, innovation of education forms and methods, establishing high-quality teachers group and improving supervision management system, etc. To effectively combine psychological health education with new media method, it can enhance the effectiveness of psychological health education in university. With the comparison, this paper draws strength of new media and proposes some suggestions which are more suitable for university students' psychological health education.
\end{abstract}

Keywords: new media, university students, psychological health, education mode

\section{INTRODUCTION}

With the rapid economic growth and development of science and technology in China, new media has received wide popularity and application, until June 2015, China already had 668 million internet users, among whom, student groups ranked first, accounting for $28.7 \%$, while almost every university students in this group are using the internet (Wang, 2015; Singh-Pillay and Sotsaka, 2017). With the development and popularization of the internet and mobile networks in our country, more and more people start to use new media such as microblogging, WeChat, $\mathrm{QQ}$, Internet TV, podcasts and portal websites, etc. Compared with the traditional media, the new media not only has many characteristics such as different kinds of form, fast transmission speed, easy and convenient access to information and rich information sources, etc., but also has better performance on strong intercommunication and wider coverage, making new media an important carrier for university students to have access to knowledge, information and interpersonal communication. Many universities has adopted new media as one of the important means for students' psychological health education (Liu, 2016; Shilova and Sibgatullina, 2017). However, any new things have two sides, so does the new media, with the positive influence that has been brought to university students' psychological health education, its negative influence is also unavoidable (Mou and Liang, 2016; Or-Kan, 2017). Therefore, facing of the big challenge brought by the rapid development of the new media to the deepening reform of university students' ideological and political education (Yang, 2014), how to maximize the advantages of new media and take advantages of the positive influence of the new media on university students' psychological 


\section{Contribution of this paper to the literature}

- This paper is not only theoretical, but through vivid examples to make original theory become more acceptable for people, data in this paper all come from real life, and it's not low-level reusing.

- Studies in this paper is comprehensive, which closely linked with each part, it not only has theoretical foundation, but also has practical research data, accurately master the substantial content of difference, which is more conducive to analyze the psychological health education methods for university students from the perspective of new media.

- It not only has macro analysis for university students' psychological health education, but also has in-depth analysis on itself, making this paper more profound, comprehensive and of practical significance.

health education, exploring the psychological health education mode for university students from the perspective of new media, this has been drawn attention by educators and researchers, which is also an important subject for deepening reform of psychological health education mode for university students (Zhang, 2016; Cochrane and Davey, 2017).

Discussing and analyzing the influence on psychological health education mode for university students from the perspective of new media is beneficial for the deepening reform of psychological health education for university students, and is also meaningful and of guiding significance for how to carry out psychological health education for university students from the perspective of new media (Guo and Wang, 2011). This paper mainly studies the current situation of university students' psychological health education from the perspective of new media, exploring the new situation and problems showed in psychological health education brought by the new media and how to improve the psychological health education for university students from the perspectives of new media. This paper enriches the psychological health education methods for university students, making its more scientific and rationalized (Chase and Klahr, 2017; Falloon, 2017).

\section{LITERATURE REVIEW}

Long time ago, scholars in the world have started using new media technology in universities. Firstly, some scholars believe that new media technology is mainly used in social communication management mechanism, such as Merweowitz in the US has proposed situational theory: new media affect social environment of a country and behavior of its people (Sit and Brudzinski, 2017). Harold Adams Innis from Canada elaborated the influence on social organization and interpersonal communication forms among people caused by media function of the new media on social communication in his book Bias of Communication, stressing to give attention the media function of the new media, and improving management mechanism as much as possible (Ling, 2012). The Japanese scholar Makiko Nakano raised "container people" theory, which indicated that new media from the outside world can affect people's self-consciousness, self-willingness and behaviors. Secondly, some other scholars have studied the influence of new media on people's behaviors, for example, Se. Dyson has pointed in his articles that people's personal privacy, security and freedom may be subject to different kinds of conflicts under the era of digital information, and the application and popularization of new media technology will ask for more responsibility and obligation from people for their behaviors and the society that they created. Some foreign scholars have found that the coming new media era will bring a very different contradiction to people's behavior and psychology, and will have both positive and negative effect on their psychological health. However, research and studies on direct connection between new media and psychological education methods are rare (Eitel et al., 2017).

As mentioned above, recent studies from foreign scholars on new media and psychological health education mode mainly focused on aspects of idea of new media, characteristics, effective factors and effectiveness, etc. There mostly were empirical research and rarely were quantitative research, the research objects are relatively general and were conducted from macro point of view, which is lack of targeted studies. This paper combines theory and practice, choosing students from 6 universities as research objects, by using data to analyze university students' psychological health education method from the perspective of new media in a more deepening and comprehensive way, providing some suggestions on psychological health education methods which accord with the development trend of new media for university students (Kant et al., 2017).

Yu Yang has elaborated the connections between university students' psychological health education, ideological and political education and characteristics of new media and analyzed its influence, pointed out that university students' psychological health education, ideological and political education must accord with characteristics of new media. In the era of new media, educators in university and universities need to change their traditional attitudes, strength learning and studying how to actively cooperate with guiding and effectively use new media to do the psychological and ideological education for university students (Taggart, 2017; Kinkead-Clark, 2017). 
Qiu Xiang from Nanjing Institute of Physical Education pointed out both challenges and opportunities that have been placed in front of university students' psychological and ideological education under the environment of new media, and provided corresponding countermeasures, such as changing their own old ideas as soon as possible, improving the quality of the media, broadening education methods and building up theme website for university students' psychological health education, etc. (Huang and Hou, 2014; Guterman, 2017).

Wang Junyong from Changchun Architecture \& Civil engineering University elaborated and analyzed the current development situation of university students' psychological health education, pointed out that new media needs to be incorporated with contemporary university students' psychological health education, constructing and perfecting a working and management mechanism of new media, thus to enhance the efficiency of university students' psychological health education.(Wang, 2014; Lai et al., 2017).

Sun Qi from Qufu Normal University researched and analyzed whether the combination of new media and the traditional media can produce positive or promoting effect on university students' psychological health education, pointed out that new media is influential and attractive and can effectively strengthen the enthusiasm for psychological health learning by university students. Educators should pay more attention to characteristics of new media and effectively combine new media with the traditional media to master this new education method which is carried with new media as its platform for university students' psychological health education (Hu, 2015; ParksStamm et al., 2017).

\section{METHODS}

This paper mainly uses the literature review method, expert interview method, questionnaire survey method and mathematical method to clarify the point of view:

\section{Literature Review Method}

Using CNKI (China National Knowledge Internet), Google Scholar, Baidu Scholar for searching literature and manual checking recent 20 years' documents and information on new media and university students' psychological health education, undertaking the statistical classification of all reviewed data and information, on the basis of generalization and summing up the related documents, the research goal and theoretical basis have been determined for this paper (Webber, 2017).

\section{Expert Interview Method}

On the basis of literature review on new media and development of psychological health education, several scholars and educators who are undertaking psychological health education research and teaching have been invited to interview, providing the idea of experts for this paper's theoretical ground (Serneels et al., 2017).

\section{Questionnaire Survey Method}

Designing questionnaire and distributing to psychological health education researchers, educators on psychological health education and university students, then collecting back and organizing the results.

\section{Mathematical Statistics Method}

Adopting principal component analysis method of spss 2010 software to analyze, generalize and sum up the data collected for this paper, selectively having data calculation and inductive analysis on targeted indexes, its steps are as follows:

First step: Standardized collection of original index data $p$ vector variable $x=\left(x_{1}, x_{2}, \ldots x_{p}\right)^{T} n$ samples $x_{i}=$ $\left(x_{i 1}, x_{i 2}, \ldots x_{i p}\right)^{T}, i=1,2, \ldots, n, n<p$, constructing the matrix, to have standardized change of sample's principal elements:

$$
Z_{i j}=\frac{x_{i j}-\bar{x}_{j}}{s_{j}}, i=1,2, \ldots, n ; j=1,2, \ldots p
$$

Among which, $\bar{x}_{j}=\frac{\sum_{i=1}^{n} x_{i j}}{n}, s_{j}^{2}=\frac{\sum_{i=1}^{n}\left(x_{i j}-\overline{x_{j}}\right)^{2}}{n-1}$, getting the standardized matrix $Z$.

Second step: find the correlation coefficient matrix of the normalized matrix $Z$ :

$$
R=\left[r_{i j}\right]_{p} x p=\frac{Z^{T} Z}{n-1}
$$




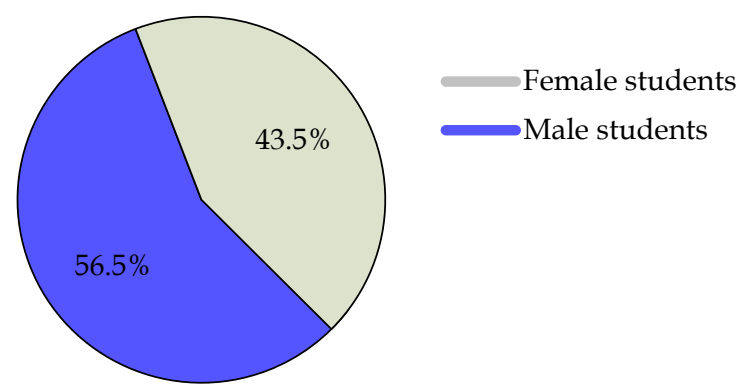

Figure 1. Gender Analysis of Questionnaire Participants

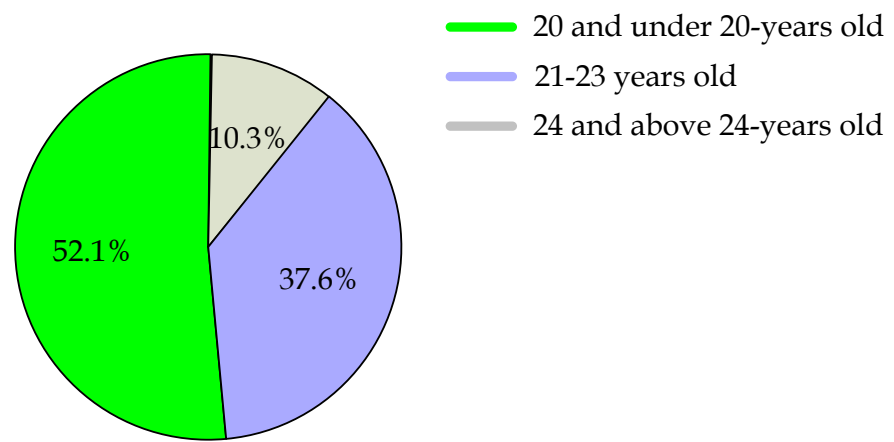

Figure 2. Age analysis of Participants

Among which, $r_{i j}=\frac{\sum z_{k j} \bullet z_{k j}}{n-1}, i, j=1,2, \ldots, p$.

Third step: solve sample correlation matrix $R^{\prime}$ s characteristic equation $\left|R-\lambda I_{p}\right|=0$ to get $p$ characteristic roots, determine the principal components, according to $\frac{\sum_{j=1}^{m} \lambda_{j}}{\sum_{j=1}^{p} \lambda_{j}} \geq 0.85$ to determine value of $m$, making the utilization ratio of the information over $85 \%$, for every $\lambda_{j}, j=1,2, \ldots, m$, solving equation group $R b=\lambda_{j} b$ to get unit eigenvector $b_{j}^{0}$.

Fourth step: converting the standardized index variables into the principal components:

$$
U_{i j}=z_{i}^{T} b_{j}^{0}, j=1,2, \ldots, m
$$

$U_{1}$ is the first principal component, $U_{2}$ is the second principal component, $\ldots, U_{\mathrm{p}}$ is the $p$ principal component.

Fifth step: Taking a weighted sum of $m$ principal components, thus can get the final evaluation value (Link et al., 2017).

\section{RESULTS}

In order to reflect survey result more clearly and accurately, this paper analyzes the results mainly from three aspects: gender, age and recognition degree of new media.

As shown in Figure 1, among effective collected questionnaires, male students were 598, accounting for 56.5\% of total number, female students were 461 , accounting for $43.5 \%$ of total number (Honig et al., 2017).

As shown in Figure 2, in this questionnaire survey, students under 20-year old were 552, accounting for 52.1\% of total valid samples, students between 21 to 23 were 398, accounting for $37.6 \%$ of total valid number, students who are 24 and over were 109, accounting for $10.3 \%$. According to the survey, recent university students were almost born after 1990s, and most of them were under 20-year old, those students mainly are new university students, and were born between 1996 to 1997, students in this age stage are curious about newly coming-out things (Flaherty et al., 2017).

According to Figure 3, among all the university participants in the research of understanding of new media, 618 participants choose general understanding, accounting for $58.4 \%$ of effective samples, 215 students chose little understanding, accounting for $20.3 \%$ of effective samples, 98 students chose very good understanding of new media, accounting for $9.3 \%$ of effective samples, 69 students chose just know about it, accounting for $6.5 \%$, 59 students chose don't understand, accounting for $5.6 \%$ of effective samples. Students who chose very good understanding and general understanding only account for $15.8 \%$ of effective samples, which is enough to indicate that recent university students have a lower degree of understanding about new media, although university 


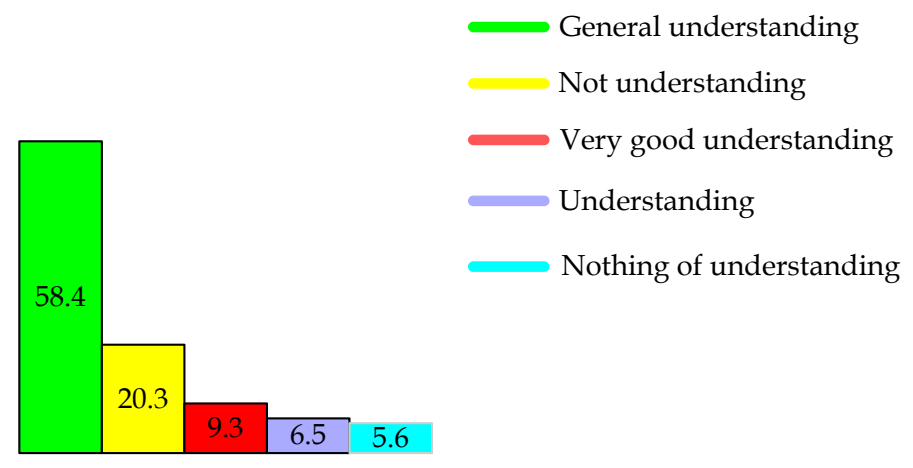

Figure 3. University Students' Understanding Degree of New Media

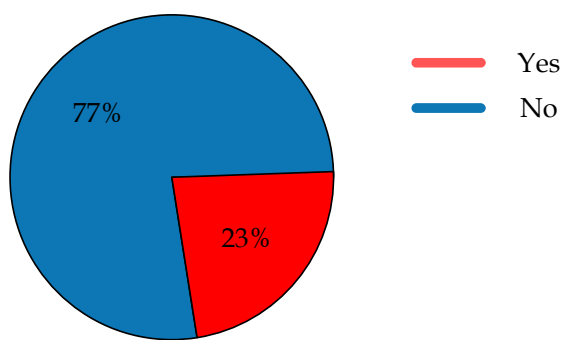

Figure 4. Psychological Health Education System with New Media as its Carrier in Universities

students are using new media in a comprehensive way, they know little about idea and development of new media, which shows a relatively low literacy about new media of university students. Therefore, strengthening the training of knowledge on new media for educators working on university students' psychological health education and paying attention to university students' understanding of new media are very important, university students should be correctly directed to use new media in more healthy and reasonable way.

The Figure 4 shows that whether the education system has combined new media with the traditional ideological and psychological education, $77 \%$ participants chose no, while only $23 \%$ chose yes, judging from this percentage, we can see that universities have not yet built a comprehensive psychological health education system by using new media as its carrier.

\section{DISCUSSION}

In order to have a better analysis of university students' psychological health mode from the perspective of new media, this paper will discuss the effect of new media to university students' psychological health education, mainly from the comparison between positive side and negative side, and lays a theoretical foundation for further conclusion and suggestions.

\section{Positive Effect of New Media on University Students' Psychological Health Education}

The tradition psychological health education for university students is based on theoretical courses, the single source of knowledge and this traditional education mode led to a poor teaching result. New media, by using smartphones, WeChat, computers and some other terminal devices, has built a powerful internet network, expanding and enriching the psychological health education methods for university students. New media can transmit originally very abstract psychological health knowledge through new forms such as vivid text, images, sounds, videos, etc., which are more vivid, intuitive, interesting and much easier to motivate students' learning interests, also, enriched information resources can fill the teaching content of psychological education for university students. Moreover, the psychological health education for university students with new media as it carrier, by taking advantages of various forms and broad coverage, can realize all-weather, time-crossed resources sharing, interactive communication on psychological health education, shortening the distance between each other and ensuring the effectiveness of psychological health education for university students. 


\section{Negative Effect of New Media on University Students' Psychological Health Education}

The newly-built internet platform through new media has strong characters of randomness and anonymity, therefore, with useful information and positive energy, it also brings many fake and trash information, those bad information and thoughts seriously affect contemporary university students' psychological health. Since new media has built a huge virtual space, this resulted in inability of university students to distinguish between real and virtual world, also, the long-time living in the relatively closed environment will lead them into cold, withdrawn and self-lost personality, and even caused many serious psychological diseases. Furthermore, since university students can freely distribute information on new media carrier, it will add more difficulty on psychological health education for university students, this situation indicates that it's urgent for educators to explore more effective education mode.

\section{CONCLUSION}

With the continuous development of science and technology, new media such as the internet, smartphones, television has been rapidly popularized, with its influence on way of life of human, its emergency, like many other new things, all has two sides. The existence of new media not only has brought positive effect for university students' living, study and psychology, but also brought negative effect because of its negative energy and false information. This paper researches and analyzes the problems caused by new media for psychological health education in university and universities, finding some new situations and problems in psychological health education for university students from the perspective of new media, exploring psychological health education mode for university students from the perspective of new media.

Since the trend has set, we should not escape but to adapt to it and maximize its benefits for solving the psychological education problems of university students from the perspective of new media, and combing the traditional education methods to provide corresponding solutions: build a comprehensive education system, enrich education content, innovate teaching content and methods, building high-quality teaching groups and improving supervision management mechanism, etc., effectively combing psychological education with new media to strengthen the effectiveness of psychological health education in universities.

\section{ACKNOWLEDGEMENT}

The research is supported by the blue engineering training project of higher school in Jiangsu province.

\section{REFERENCES}

Chase, C. C., \& Klahr, D. (2017). Invention versus direct instruction: for some content, it's a tie. Journal of Science Education and Technology, 26(6), 582-596. doi:10.1007/s10956-017-9700-6

Cochrane, T., \& Davey, R. C. (2017). Mixed-methods evaluation of a healthy exercise, eating, and lifestyle program for primary schools. Journal of School Health, 87(11), 823-831. doi:10.1111/josh.12555

Eitel, A., Benito, S. M., \& Scheiter, K. (2017). Do it twice! Test-taking fosters repeated but not initial study of multimedia instruction. Learning and Instruction, 5, 236-45. doi:10.1016/j.leaminstruc.2017.04.003

Falloon, G. (2017). Mobile devices and apps as scaffolds to science learning in the primary classroom. Journal of Science Education and Technology, 26(6), 613-628. doi:10.1007/s10956-017-9702-4

Flaherty, A. A., O’Dwyer, A., Mannix-McNamara, P., \& Leahy, J. J. (2017). The Influence of Psychological Empowerment on the Enhancement of Chemistry Laboratory Demonstrators' Perceived Teaching SelfImage and Behaviours as Graduate Teaching Assistants. Chemistry Education Research and Practice, 18(4), 710736.

Guo, F., \& Wang, Z. B. (2011). Investigation and Analysis on Psychological Resilience of Higher Vocational School Students-The Case of Three Higher Vocational Schools in Jiangsu Province. Vocational and Technical Education, 32(31), 60-63.

Guterman, O. (2017). What makes a social encounter meaningful: the impact of social encounters of homeschooled children on emotional and behavioral problems? Education and Urban Society, 49(8), 778-792. doi:10.1177/0013124516677009

Honig, M. I., Venkateswaran, N., \& McNeil, P. (2017). Research Use as Learning: The Case of Fundamental Change in School District Central Offices. American Educational Research Journal, 54(5), 938-971.

Hu, P., \& Chen, Y. W. (2015). The Construction and Application of Evaluation System of College Students' Mental Health Education. Heilongiiang Researches on Higher Education, 256(8), 100-103. 
Huang, H., \& Hou, J. X. (2014). A comparative analysis on mental health of college students with internet addiction and mobile phone addiction. Chinese Journal of School Health, 11(35), 1654-1659.

Kant, J. M., Scheiter, K., \& Oschatz, K. (2017). How to sequence video modeling examples and inquiry tasks to foster scientific reasoning. Learning and Instruction, 52, 46-58. doi:10.1016/j.learninstruc.2017.04.005

Kinkead-Clark, Z. (2017). Bridging the gap between home and school perceptions of classroom teachers and principals: case studies of two Jamaican inner-city schools. Education and Urban Society, 49(8), 762-777. doi:10.1177/0013124516658951

Lai, P. K., Portolese, A., \& Jacobson, M. J. (2017). Does sequence matter? Productive failure and designing online authentic learning for process engineering. British Journal of Educational Technology, 48(6), 1217-1227. doi:10.1111/bjet.12492

Ling, H. (2012). Innis's view of communication bias and the crisis of Western civilization. Jiangxi Social Sciences, (10), 229-232.

Link, H., Gallo, S., \& Wortham, S. E. (2017). The Production of Schoolchildren as Enlightenment Subjects. American Educational Research Journal, 54(5), 834-867.

Liu, D. (2016). The impact and Countermeasures of New Media on College Students' Society - adapting Ability. Heilongiiang Researches on Higher Education, 263(3), 99-101.

Mou, Y. J, \& Liang, C. X. (2016). The Negative Impact of the New Media Environment on Mental Health of College Students and Countermeasures. Journal of Guilin Normal University, 108(4), 89-91.

Or-Kan, S. (2017). Processing academic science reading texts through context effects: evidence from eye movements. EURASIA Journal of Mathematics, Science and Technology Education, 13(3), 771-790. doi:10.12973/eurasia.2017.00642a

Parks-Stamm, E. J., Zafonte, M., \& Palenque, S. M. (2017). The effects of instructor participation and class size on student participation in an online class discussion forum. British Journal of Educational Technology, 48(6), 12501259. doi:10.1111/bjet.12512

Serneels, P., Beegle, K., \& Dillon, A. (2017). Do returns to education depend on how and whom you ask? Economics of Education Review, 60, 5-19.

Shilova, Z. V., \& Sibgatullina, T. V. (2017). Methodology features of teaching stochastics to university students of the biology specialization. EURASIA Journal of Mathematics, Science and Technology Education, 13(8), 47254738. doi:10.12973/eurasia.2017.00960a

Singh-Pillay, A., \& Sotsaka, D. S., (2017). Engineering graphics and design teachers' understanding and teaching of assembly drawing. EURASIA Journal of Mathematics, Science and Technology Education, 13(5), 1213-1228. doi:10.12973/eurasia.2017.00668a

Sit, S. M., \& Brudzinski, M. R. (2017). Creation and assessment of an active e-learning introductory geology course. Journal of Science Education and Technology, 26(6), 629-645. doi:10.1007/s10956-017-9703-3

Taggart, A. (2017). The role of cultural discontinuity in the academic outcomes of latina/o high school students. Education and Urban Society, 49(8), 731-761. doi:10.1177/0013124516658522

Wang, J. Y. (2014). The current situation and Countermeasures of Ideological and political education of college students from the perspective of new media. Business, (32), 194-194.

Wang, Z. L. (2015). Smartphones and the "Internet + Class": A New Thinking and New Pattern of Information Technology Integrated into Curriculum. Journal of Distance Education, (4), 14-21.

Webber, D. A. (2017). State divestment and tuition at public institutions. Economics of Education Review, 60, 1-4.

Yang, X. (2014). Analysis of countermeasures for ideological and political education of University Students under the new media vision. Heilongjiang Researches on Higher Education, 248(12), 137-139.

Zhang, C. (2016). A Brief Discussion on Psychological Health Education for University Students in the New Media Era. The Science Education Article Collects, 347(11), 137-138.

\section{http://www.ejmste.com}

